\title{
Genetic and epigenetic changes in the common I 36 deletion in neuroblastoma tumours
}

\author{
H Carén', S Fransson', K Ejeskär', P Kogner² and T Martinsson*,I \\ 'Department of Clinical Genetics, Institute of Biomedicine, Göteborg University, Sahlgrenska University Hospital, Göteborg SE-4 I 345, Sweden; ${ }^{2}$ Childhood \\ Cancer Research Unit, Department of Woman and Child Health, Karolinska Institutet, Karolinska Hospital, Stockholm SE-I 7 I 76, Sweden
}

Chromosome I $\mathrm{p}$ is frequently deleted in neuroblastoma (NB) tumours. The commonly deleted region has been narrowed down by loss of heterozygosity studies undertaken by different groups. Based on earlier mapping data, we have focused on a region on Ip36 (chrl: $7765595-1$ I 0198 |4) and performed an analysis of 30 genes by exploring features such as epigenetic regulation, that is DNA methylation and histone deacetylation, mutations at the DNA level and mRNA expression. Treatment of NB cell lines with the histone deacetylase inhibitor trichostatin $A$ led to increased gene transcription of four of the 30 genes, ERRFII (MIG-6), PIK3CD, RBP7 (CRBPIV) and CASZI, indicating that these genes could be affected by epigenetic downregulation in NBs. Two patients with nonsynonymous mutations in the PIK3CD gene were detected. One patient harboured three variations in the same exon, and p.RI88W. The other patient had the variation p.M655I. In addition, synonymous variations and one variation in an intronic sequence were also found. The mRNA expression of this gene is downregulated in unfavourable, compared to favourable, NBs. One nonsynonymous mutation was also identified in the ERRFII gene, p.N343S, and one synonymous. None of the variations above were found in healthy control individuals. In conclusion, of the 30 genes analysed, the PIK3CD gene stands out as one of the most interesting for further studies of NB development and progression.

British Journal of Cancer (2007) 97, I4I6-1424. doi:1 0. I038/sj.bjc.6604032 www.bjcancer.com

Published online 16 October 2007

(c) 2007 Cancer Research UK

Keywords: neuroblastoma; Ip; mutation; epigenetics; PIK3CD

Neuroblastoma (NB) is the most common extracranial tumour of childhood (Gale et al, 1982). One of the hallmarks of NB tumours is their clinical heterogeneity, ranging from spontaneous regression to malignant disease. Deletion of the short arm of chromosome 1 (1p-deletion), additional genetic material from the long arm of chromosome 17 (17q gain) and amplification of the proto-oncogene $M Y C N$ are examples of chromosomal abnormalities that have been found in NB. The $1 p$ region has been subjected to intense study in this tumour type; it shows loss of heterozygosity $(\mathrm{LOH})$ in $20-40 \%$ of NB tumours. 1p-deletion is also highly correlated with $M Y C N$ amplification and predicts unfavourable outcome (Caron et al, 1996). It has therefore been proposed that the region contains a tumour suppressor gene that is inactivated in aggressive NB tumours.

The deletion of chromosome 1 often involves a large proportion of $1 \mathrm{p}$ but some tumours display smaller deletions. Our group, as well as others, has tried to identify the critical region/regions by comparing the deletions found in the tumours. We have defined the shortest region of overlap (SRO) of deletions in our tumour material to about $25 \mathrm{cM}$ located between the markers D1S80 and D1S244 (Martinsson et al, 1995, 1997). By the addition of germ cell tumours, an approximately $5 \mathrm{cM}$ combined SRO of deletions was

*Correspondence: Dr T Martinsson;

E-mail: tommy.martinsson@clingen.gu.se

Received II June 2007; revised 10 September 2007; accepted 17 September 2007; published online 16 October 2007 defined by markers D1S508 and D1S244 (Ejeskär et al, 2001). As an overlapping homozygous $500 \mathrm{~kb}$ deletion of $1 \mathrm{p} 36.2-3$ was found in an NB cell line (Ohira et al, 2000), the region has been analysed in further detail. In our study of the genes within this region, all seven were screened for mutations and a few were indeed discovered (Ejeskär et al, 2000; Abel et al, 2002, 2004; Krona et al, 2003, 2004). We have also explored the expression and methylation status of these genes. The transcripts have been shown to be downregulated in unfavourable $\mathrm{NB}$, compared to favourable $\mathrm{NB}$, a feature that cannot be explained by methylation of their respective $\mathrm{CpG}$ islands (Carén et al, 2005). In the current study, we wanted to expand our investigation of the $1 \mathrm{p}$ region, more specifically to our combined $\mathrm{NB} /$ germ cell SRO of deletions, and to explore epigenetic mechanisms in the regulation of possible tumour suppressor genes. The effect of DNA methylation and histone deacetylation events of 30 genes in the 1 p36 chromosomal region extending from markers D1S508 and D1S244, bp 7765595-11019814 (UCSC version, May 2004; URL: http://genome.ucsc.edu) were explored. This SRO of deletions is in agreement with SRO studies presented by other groups (Caron et al, 2001; Chen et al, 2001). Yet, other groups have presented SRO located more distal on 1p (Bauer et al, 2001; White et al, 2005).

Genes identified as possibly regulated by epigenetic means were studied further with expression analysis and mutation screening of primary tumours. A small number of the $1 \mathrm{p}$ genes studied showed indication of epigenetic inactivation and two of these also contained mutations in NB tumours. 


\section{MATERIALS AND METHODS}

\section{Cell lines and patients}

A panel of 66 primary NB tumours of different stages was used in the study, 35 tumours were used for expression analysis; 17 tumours with favourable biology from patients with no evidence of disease and 18 tumours with unfavourable biology from patients who have died from the disease and 46 for DNA sequencing (Table 1). Fifteen of the samples were used for both expression and sequencing analysis. Also, 120 healthy control individuals were used for DNA sequencing. For cell treatments, three NB cell lines with 1p-deletion (IMR-32, SK-N-AS, SK-N-BE(2)) and one with intact $1 \mathrm{p}$ (SH-SY5Y) were used. These and five other NB cell lines (SK-N-DZ, SK-N-F1, SK-N-SH, Kelly and NB69) were used for bisulphite sequencing.

\section{Analysis of methylation and acetylation status}

Cells were seeded at low density and treated with the demethylating agent 5-Aza-2'-deoxycytidine (5-Aza-dC) (Sigma-Aldrich Co, St Louis, MO, USA) or with the histone deacetylase inhibitor trichostatin A (TSA; Sigma-Aldrich) on the day after seeding. Different concentrations and exposure durations were investigated and a concentration of 2 or $4 \mu \mathrm{m}$ of 5 -Aza-dC for $72 \mathrm{~h}$ and $0.5 \mu \mathrm{M}$ of TSA for $16 \mathrm{~h}$ were chosen. The experiments were repeated twice and medium was changed every second day to fresh medium containing the respective agents. As controls, the respective cell lines were mock treated with the same amount of carrier (EtOH for the TSA treatments and DPBS; Dulbecco's buffered saline, PAA Laboratories, Linz, Austria, for 5-Aza-dC).

\section{Expression analysis}

cDNA preparation Total RNA was extracted from the cell lines using the RNeasy RNA extraction kit (Qiagen, Hilden, Germany). Total RNA from NB tumour samples was extracted using the RNA extraction kit or Totally RNA (Ambion, Austin, TX, USA). Total RNA, $1 \mu \mathrm{g}$, was reverse transcribed to cDNA using Superscript II (Amersham, Buckinghamshire, UK) and random hexamer primers, all according to the protocol of the supplier. The cDNA samples were quality-tested by amplification of the GUSB ( $\beta$-glucuronidase) gene.

Real-time RT-PCR - endogenous control The GUSB gene was used as an endogenous control for normalisation of expression in the tumour samples. This gene has previously been shown to be expressed at constant levels in tumour samples, regardless of NB stage (Abel et al, 2005). In order to select the most appropriate endogenous control for the NB cell lines, untreated and treated cell lines were tested for their expression levels of seven commonly used housekeeping genes using TaqMan ${ }^{\mathrm{B}}$ Assays-on-Demand ${ }^{\mathrm{TM}}$ Gene Expression Products (Applied Biosystems, Foster City, CA, USA). Analysis was performed with geNorm 3.4 software (Vandesompele et al, 2002) which determines the most stable housekeeping genes in a set of genes in the cDNA panel. GUSB, $U B C$ ( $\beta_{2}$-microglobulin) and SDHA (succinate dehydrogenase) showed the smallest variations in $\Delta C_{\mathrm{T}}$ levels and were expressed at constant levels in samples regardless of treatment; these genes were therefore used as internal references for normalisation in the real-time RT-PCR quantification analysis for the NB cell lines.

Real-time RT-PCR - TaqMan TaqMan primers and probes were derived from Applied Biosystems. Real-time RT-PCR was performed in 384-well plates using the ABI PRISM ${ }^{\circledR} 7900 \mathrm{HT}$ Sequence Detection System (Applied Biosystems). Amplification reactions $(10 \mu \mathrm{l})$ were carried out in duplicate with $0.1 \mu \mathrm{l}$ template cDNA, according to the protocol of the manufacturer (Applied Biosystems). A standard curve with six cDNA dilutions was recorded and two nontemplate controls were included in each assay.

Quantification was performed by the standard curve method, as described previously (Abel et al, 2005). Briefly, the mean $C_{\mathrm{T}}$-value for duplicates was calculated, and the gene concentration (or gene copy numbers) of test samples was interpolated based on standard curves. All samples were normalised by dividing the concentration of the test gene with the concentration of the housekeeping gene/ genes in the same cDNA sample.

The logarithms of the expression levels in favourable and unfavourable NB tumours were compared using Student's twosided $t$-test. Box plots were constructed using SPSS 12.0.1 for Windows.

\section{Confirmation of methylation status}

Bisulphite modification DNA was phenol-extracted using phase lock gel (Eppendorf AG, Hamburg, Germany) according to standard procedure and was, with some minor changes, modified with bisulphite according to previously published papers (Clark et al, 1994; Paulin et al, 1998). Briefly, $1 \mu \mathrm{g}$ of genomic DNA was treated with restriction endonucleases that digested the DNA close to, but outside, the region of interest. The DNA was then denatured in $0.3 \mathrm{M}$ freshly prepared $\mathrm{NaOH}$ at $40^{\circ} \mathrm{C}$ for $15 \mathrm{~min}$. Sodium metabisulphite (Sigma-Aldrich) and urea, at final concentrations of $1.73 \mathrm{M}$ and $5.36 \mathrm{M}$, respectively, were added in order to sulphonate the unmethylated cytosines, together with hydroquinone $(0.5 \mathrm{~mm})$. Conversion was carried out at $55^{\circ} \mathrm{C}$ for $16 \mathrm{~h}$, with a temperature increase to $95^{\circ} \mathrm{C}$ for $30 \mathrm{~s}$ every $3 \mathrm{~h}$. DNA was purified with the Wizard DNA cleanup system (Promega Corporation, Madison, WI, USA), according to the instructions of the manufacturer, and desulphonated in $0.3 \mathrm{M} \mathrm{NaOH}$ at $37^{\circ} \mathrm{C}$ for $15 \mathrm{~min}$ and finally precipitated in ethanol, resuspended in distilled $\mathrm{H}_{2} \mathrm{O}$ and stored at $-20^{\circ} \mathrm{C}$. Universally Methylated DNA (Chemicon International, Temecula, CA, USA) was included as a positive control for methylation.

Promoter analysis and DNA amplification Prediction of promoters associated with $\mathrm{CpG}$ islands were done with CpGProD (Ponger and Mouchiroud, 2002) and CpG islands were also searched with $\mathrm{CpG}$ island searcher (URL: http://cpgislands.usc. $\mathrm{edu}$ ). Criteria for $\mathrm{CpG}$ island selection were chosen according to Takai and Jones (2002), that is an expected GC content of $>55 \%$, an observed/expected $\mathrm{CpG}$ ratio of $>0.65$ and $>500 \mathrm{bp}$. The regions were also searched with relaxed criteria's. The regions, or parts of them, were amplified with one primer pair or, if required, with nested primers (primer sequences available on request). The methylation status was analysed using bisulphite sequencing. Touchdown PCR was performed with $1 \times$ Reaction Buffer, $0.5 \mathrm{~mm}$ dNTPs, $2.0-3.0 \mathrm{mM} \mathrm{MgCl}_{2}, 0.4 \mu \mathrm{M}$ of forward and reverse primers, respectively, and $1 \mathrm{U}$ of HotStar Taq (Qiagen, Hilden, Germany), in a total volume of $20 \mu \mathrm{l}$. Reactions were denatured at $95^{\circ} \mathrm{C}$ for $15 \mathrm{~min}$, followed by five cycles of $95^{\circ} \mathrm{C}$ for $1 \mathrm{~min}, 5^{\circ} \mathrm{C}$ above annealing temperature with a decrease of $1^{\circ}$ per cycle for $1 \mathrm{~min}$, $72^{\circ} \mathrm{C}$ for $1 \mathrm{~min}$ and 30 cycles of $95^{\circ} \mathrm{C}$ for $1 \mathrm{~min}$, annealing temperature for $1 \mathrm{~min}, 72^{\circ} \mathrm{C}$ for $1 \mathrm{~min}$ and ending with $7 \mathrm{~min}$ extension at $72^{\circ} \mathrm{C}$. PCR products were purified with ExoSAP-IT ${ }^{\mathrm{TM}}$ (USB Corporation, Cleveland, OH, USA) and sequencing was carried out using forward or reverse primer with the ABI Prism BigDye $^{\mathrm{TM}}$ cycle sequencing Ready Reaction Kit (Applied Biosystems). The samples were analysed in an ABI 3100 Genetic Analyzer or an ABI 3730 Genetic Analyzer (Applied Biosystems). Sequence analysis was conducted with SeqScape version 2.1.1 (Applied Biosystems). 
Table I Clinical data of primary neuroblastoma used in the study

\begin{tabular}{|c|c|c|c|c|c|}
\hline Patient & Stage & Outcome & Ip-del & $\begin{array}{l}\text { MYCN } \\
\text { amplification }\end{array}$ & $\begin{array}{l}\text { Group in } \\
\text { expression } \\
\text { analysis }\end{array}$ \\
\hline $35 R 8$ & I & NED & Neg & Neg & $\mathrm{F}$ \\
\hline 14E6 & 1 & NED & Neg & Neg & $\mathrm{F}$ \\
\hline |6E| & I & NED & $\mathrm{Neg}$ & $\mathrm{Neg}$ & $\mathrm{F}$ \\
\hline I8E5 & I & NED & $\mathrm{Neg}$ & $?$ & $\mathrm{~F}$ \\
\hline IOR7 & I & NED & $\mathrm{Neg}$ & $\mathrm{Neg}$ & $\mathrm{F}$ \\
\hline 26R9 & I & NED & $\mathrm{Neg}$ & $\mathrm{Neg}$ & $\mathrm{F}$ \\
\hline 9R2 & I & NED & $\mathrm{Neg}$ & $\mathrm{Neg}$ & $\mathrm{F}$ \\
\hline 30R9 & I & NED & $\mathrm{Neg}$ & Neg & $\mathrm{F}$ \\
\hline $25 R 7$ & I & NED & $\mathrm{Neg}$ & $\mathrm{Neg}$ & \\
\hline 19R6 & I & DOD & Pos & Pos & \\
\hline $25 R 9$ & 2 & NED & $\mathrm{Neg}$ & $\mathrm{Neg}$ & $\mathrm{F}$ \\
\hline 20R9 & 2 & NED & Neg & Neg & $\mathrm{F}$ \\
\hline $23 R 4$ & 2 & NED & $\mathrm{Neg}$ & $\mathrm{Neg}$ & $\mathrm{F}$ \\
\hline $25 R 8$ & 2 & NED & $\mathrm{Neg}$ & $\mathrm{Neg}$ & $\mathrm{F}$ \\
\hline $35 R 2$ & 2 & NED & $\mathrm{Neg}$ & $\mathrm{Neg}$ & $\mathrm{F}$ \\
\hline $35 R 3$ & 2 & NED & Neg & $\mathrm{Neg}$ & $\mathrm{F}$ \\
\hline I3R3 & $2 \mathrm{~A}$ & NED & $\mathrm{Neg}$ & $\mathrm{Neg}$ & $\mathrm{F}$ \\
\hline 27RI & $2 \mathrm{~A}$ & NED & Neg & $\mathrm{Neg}$ & $\mathrm{F}$ \\
\hline I4R9 & $2 B$ & NED & Pos & $\mathrm{Neg}$ & \\
\hline 33R7 & $2 B$ & NED & Neg & $\mathrm{Neg}$ & $\mathrm{F}$ \\
\hline $12 R 4$ & 3 & NED & Pos & $\mathrm{Neg}$ & \\
\hline I5R8 & 3 & NED & Pos & Neg & \\
\hline I6R4 & 3 & NED & Neg & Pos & \\
\hline 20R8 & 3 & NED & Pos & Pos & \\
\hline 23R2 & 3 & NED & Pos & Pos & \\
\hline 30R7 & 3 & $?$ & Pos & Pos & \\
\hline I3E5 & 3 & DOD & Neg & Pos & \\
\hline $13 \mathrm{E} 6$ & 3 & DOD & Pos & Pos & \\
\hline 6E9 & 3 & DOD & Neg & Neg & \\
\hline IOR8 & 3 & DOD & Pos & Neg & \\
\hline$|3 R|$ & 3 & DOD & Pos & Pos & UF \\
\hline 9R9 & 3 & DOD & Pos & $\mathrm{Neg}$ & UF \\
\hline I0E6 & 4 & NED & Pos & Pos & \\
\hline 23R5 & 4 & NED & Neg & Neg & \\
\hline 23R8 & 4 & NED & Pos & Pos & \\
\hline 24R3 & 4 & NED & Pos & Pos & \\
\hline $33 R 9$ & 4 & NED & $\mathrm{Neg}$ & Neg & \\
\hline I IR6 & 4 & NED & Pos & Pos & \\
\hline I2R9 & 4 & NED & Pos & Pos & \\
\hline 29R2 & 4 & NED & Pos & Pos & \\
\hline $32 R 2$ & 4 & NED & Pos & Neg & \\
\hline 27R4 & 4 & DOD & $\mathrm{Neg}$ & Neg & UF \\
\hline 18E4 & 4 & DOD & Pos & Pos & UF \\
\hline IOR2 & 4 & DOD & Pos & Pos & UF \\
\hline I3R0 & 4 & DOD & Pos & Pos & UF \\
\hline I5R3 & 4 & DOD & Pos & $\mathrm{Neg}$ & UF \\
\hline 26R8 & 4 & DOD & Pos & Pos & UF \\
\hline $28 R 8$ & 4 & DOD & $\mathrm{Neg}$ & $\mathrm{Neg}$ & UF \\
\hline IOE7 & 4 & DOD & $\mathrm{Neg}$ & Neg & UF \\
\hline $12 \mathrm{E} 6$ & 4 & DOD & $\mathrm{Neg}$ & Pos & UF \\
\hline I5E5 & 4 & DOD & Pos & $\mathrm{Neg}$ & UF \\
\hline 16E3 & 4 & DOD & Pos & Pos & UF \\
\hline 17E4 & 4 & DOD & Pos & Pos & UF \\
\hline $4 \mathrm{EI}$ & 4 & DOD & $\mathrm{Neg}$ & $\mathrm{Neg}$ & UF \\
\hline I7R2 & 4 & DOD & $\mathrm{Neg}$ & Neg & UF \\
\hline IIE2 & 4 & DOD & $\mathrm{Neg}$ & $\mathrm{Neg}$ & UF \\
\hline 9E5 & 4 & DOD & Pos & Pos & UF \\
\hline 18E9 & 4 & DOD & Pos & Pos & \\
\hline IIR9 & 4 & DOD & Pos & Neg & \\
\hline $12 R 6$ & 4 & DOD & Pos & Pos & \\
\hline I7R4 & 4 & DOD & Pos & Pos & \\
\hline I9R0 & 4 & DOD & Pos & Neg & \\
\hline 2IR0 & 4 & DOD & Pos & Pos & \\
\hline $23 R 7$ & 4 & DOD & Pos & Pos & \\
\hline 34R0 & 4 & DOD & Neg & Neg & \\
\hline 12E3 & 4 & DOD & Pos & Pos & \\
\hline IIE5 & $4 S$ & DOD & Neg & Neg & \\
\hline I4R2 & $4 \mathrm{~S}$ & DOD & Pos & Pos & \\
\hline
\end{tabular}

$\mathrm{NED}=\mathrm{no}$ evidence of disease; $\mathrm{DOD}=$ dead of disease; $|\mathrm{p}-\mathrm{de}|=\mid \mathrm{p}$-deletion: $\mathrm{Pos}=$ positive; $\mathrm{Neg}=$ negative; $\mathrm{F}=$ favourable; UF = unfavourable.

\section{DNA mutation screening}

DNA amplification Primers were designed for the exons and flanking intronic sequences using the Exonprimer feature of the UCSC genome browser (URL: http://genome.ucsc. edu/) and were ordered from Life Technologies, Inc., Gaitherburg, MD, USA (primer sequences available on request). Standard reactions of $20 \mu \mathrm{l}$ were used, containing 25-100 ng DNA, $1.5 \mathrm{mM} \mathrm{MgCl}_{2}, 2 \mathrm{~mm}$ dNTP, $0.6-0.75 \mu \mathrm{M}$ primer and $1 \mathrm{U}$ Taq polymerase (Amersham Pharmacia Biotech, Freiburg, Germany). Reactions were denatured at $95^{\circ} \mathrm{C}$ for $2 \mathrm{~min}$, followed by 35 cycles of $95^{\circ} \mathrm{C}$ for $30 \mathrm{~s}$, annealing for $30 \mathrm{~s}, 72^{\circ} \mathrm{C}$ for $1 \mathrm{~min}$, and ending with a $7 \mathrm{~min}$ extension step. Purification of PCR reactions and sequencing were performed as described above.

\section{RESULTS}

\section{Expression analysis of cells treated with TSA and 5-Aza-dC}

GUSB, UBC and SDHA were selected as endogenous controls for realtime RT-PCR quantification and used as internal references for normalisation. Four of the genes in the study, ERRFI1 (MIG-6), PIK3CD, RBP7 (CRBPIV) and CASZ1, were upregulated more than twofold after treatment with TSA (Table 2) in both experiments. Expression of gene transcripts of these four genes was analysed in primary $\mathrm{NB}$ tumours and the DNA sequences were analysed for mutations. Three genes, PIK3CD, RBP7 and CASZ1, were upregulated in at least two of the cell lines after treatment with 5Aza-dC. These genes were analysed further with bisulphite sequencing.

\section{Bisulphite sequencing}

CASZ1, PIK3CD and RBP7 were studied with bisulphite sequencing. Three CpG islands were studied in CASZ1 and PIK3CD. One or two fragments in each island were PCR amplified and sequenced following bisulphite modification. For location of CpG islands relative to the respective gene, see Figure 1. In our material, NB cell lines generally were found to have more methylated $\mathrm{CpG}$ sites than primary NB tumours (Figure 2). No consistent CpG methylation sites distinguishing DNA from primary tumours from that of healthy blood control DNA could be identified. The fragment analysed in the $\mathrm{CpG}$ island of $R B P 7$ was unmethylated in all cell lines.

\section{Expression analysis of NB tumours}

Expression analysis of ERRFI1, PIK3CD, RBP7 and CASZ1 was performed comparing 17 tumours with favourable biology from patients with no evidence of disease and 18 tumours with unfavourable biology (dead of disease). The expression of PIK3CD was significantly lower $(P=0.001$ after Bonferroni correction), in unfavourable tumours as compared to favourable NB (PIK3CD: fold change $(\mathrm{fc})=-2.5, P=0.0002 ; C A S Z 1: \mathrm{fc}=-2.0, P=0.03)$. No significant difference in expression of ERRFI1 $(\mathrm{fc}=+2.1$, $P=0.07)$ or $R B P 7(\mathrm{fc}=-1.1, P=0.73$ ) between favourable and unfavourable tumours could be shown (Figure 3 ).

\section{DNA sequencing}

Several sequence variations were identified in ERRFI1 and PIK3CD (see Table 3 for a summary). Three patients harboured mutations with amino-acid changes in the ERRFI1 and PIK3CD genes. In exon 5 in $P I K 3 C D$, three changes were found in the same tumour, $24 \mathrm{R} 3$ (see Figure 4). The change, $448 \mathrm{G}>\mathrm{A}$, give rise to an aminoacid substitution from the nonpolar amino-acid alanine to the polar threonine, the $469 \mathrm{C}>\mathrm{A}$ substitution from leucine to methionine (both nonpolar) and $562 \mathrm{C}>\mathrm{T}$ leads to an amino-acid substitution from the polar arginine to the nonpolar tryptophan. 
Table 2 Analysis of expression of 30 genes after treatment of NB cell lines with 5-Aza-dC or TSA

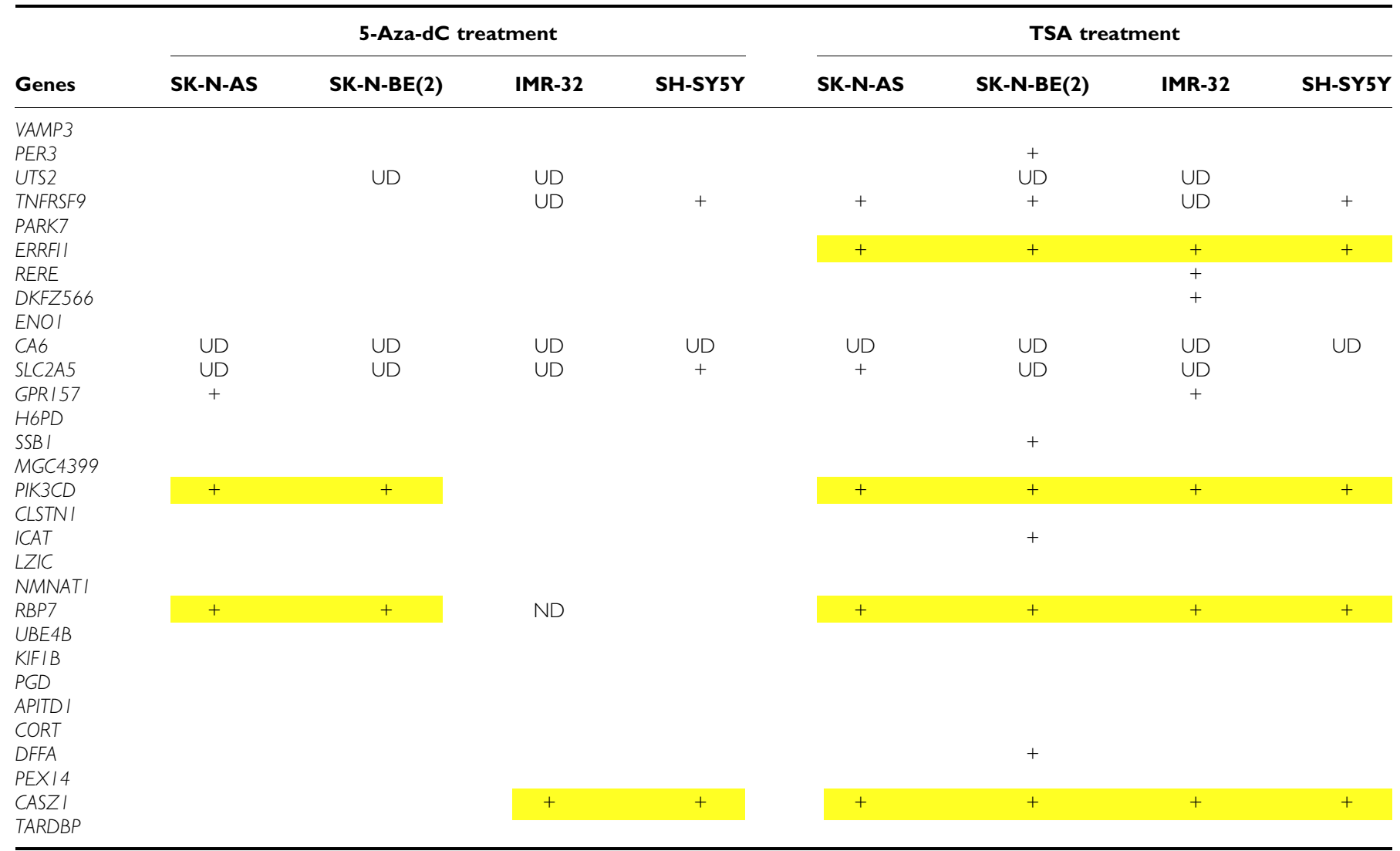

$\mathrm{UD}=$ undetermined, gene transcripts not detected in the real-time PCR amplification. ND = not determined. Genes showing consistant upregulation after treatment are highlighted in yellow.

CASZ1

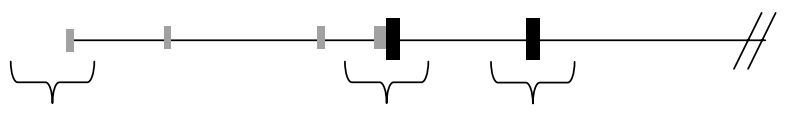

CpG island 1:

$$
-103572 \text { to }-99528
$$

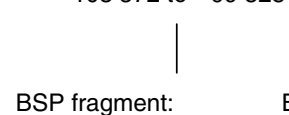
-102784 to -102560

No methylation

CpG island 2: $\quad \mathrm{CpG}$ island 3:

-1618 to $+525+28210$ to +28857

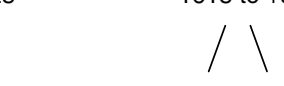

BSP fragment 1:

-1600 to -1383

Methylation: mostly
BSP fragment 2: -262 to +248

No methylation

No methylation in cell lines

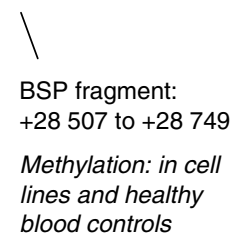
lines and healthy
blood controls
RBP7

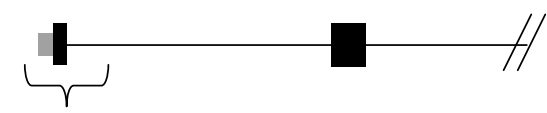

CpG island:

-546 to +1212

BSP fragment:

-223 to +79

No methylation

\section{PIK3CD}

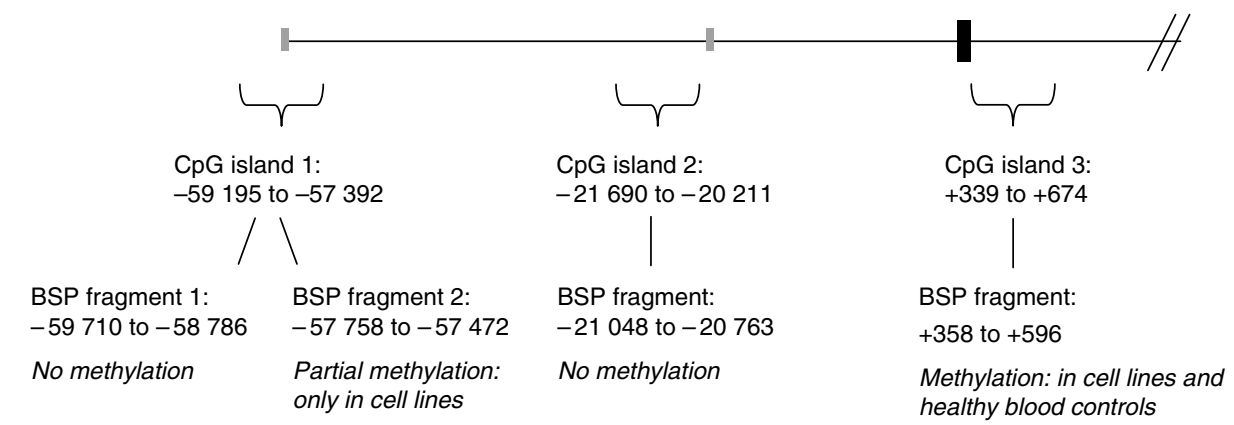

Figure I The CASZI, RBP7 and PIK3CD genes. Black boxes indicate coding exons and grey boxes untranslated exons. Positions with the A in the initiator Met codon denoted nucleotide + I. CpG islands number 3 in CASZI and PIK3CD were identified with relaxed searching criteria (an expected GC content of $>50 \%$, an observed/expected CpG ratio of $>0.6$ and $>200 \mathrm{bp})$. 
A

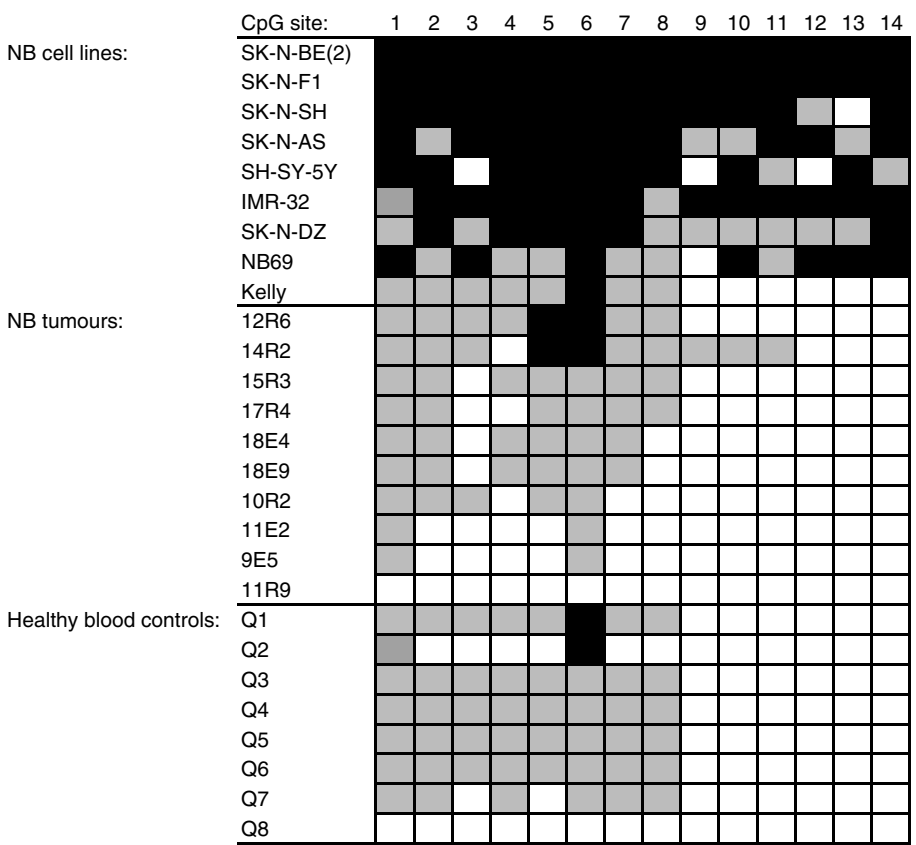

B

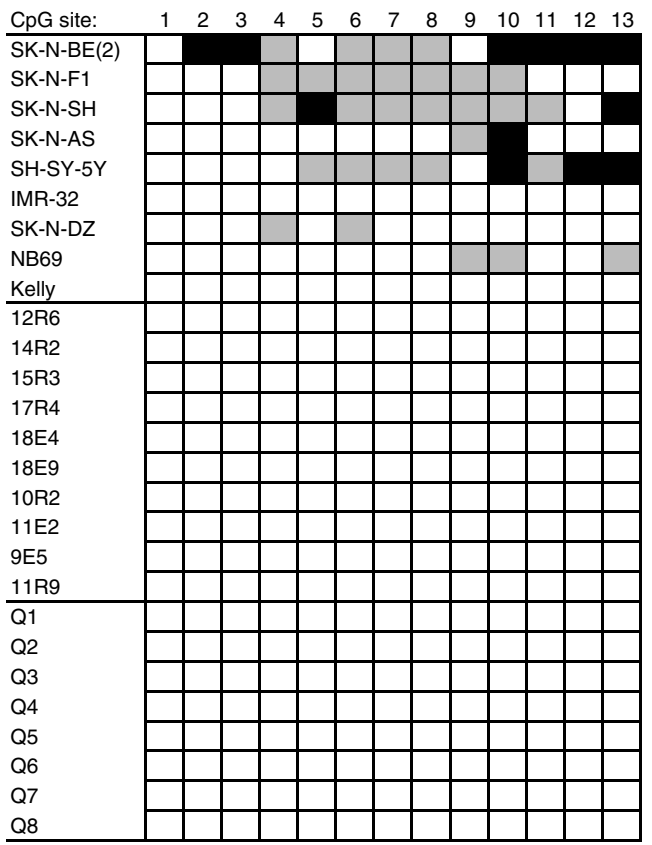

Figure 2 Methylation status of (A) CASZI CPG island 2 fragment I and (B) PIK3CD CpG island I fragment 2. Black boxes indicate methylation, grey boxes partial methylation and white boxes no methylation.
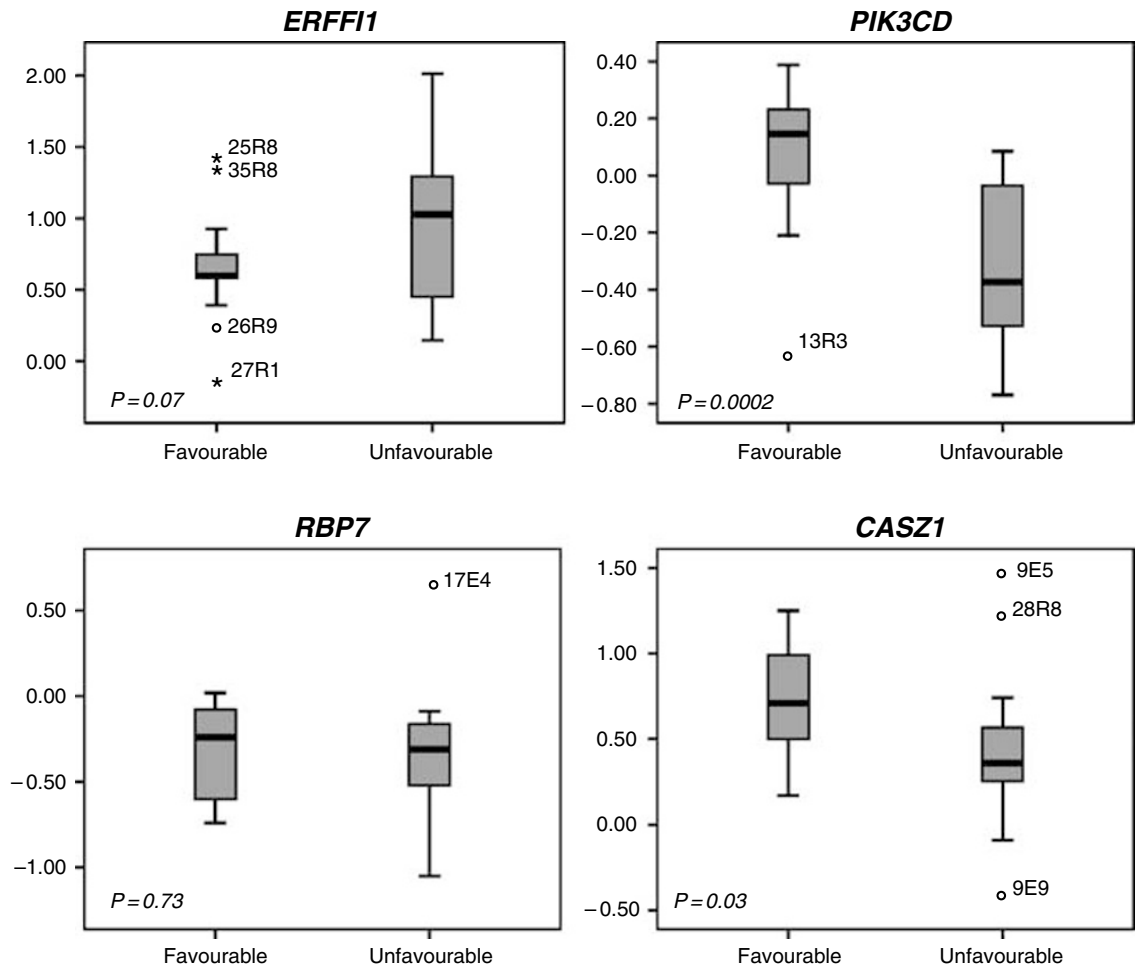

Figure 3 Relative expression of tumours with favourable biology compared to tumours of unfavourable biology. Box plot explanation; upper and lower hinge of the box represent 75th percentile and 25th percentile, respectively; whiskers indicates range; thick horizontal line within box, median. Open circles represent outliers and asterisks represent extremes. The P-value at gene-by-gene level is indicated in lower left corner in each graph.

The changes are de novo mutations, not present in constitutional DNA from the tumour. In exon 16 in PIK3CD, methionine (codon ATG) is changed to isoleucine (codon ATA) in tumour 19R6. The tumour is hemizygous for the variation as the other allele is deleted in the tumour; normal tissue from the patient is heterozygous for the variation. In ERRFI1, an amino-acid change from aspartic acid to serine, p.N343S, was found in exon 4, 1028A $>$ G (see Figure 5). This variation was also found in the constitutional DNA from the same patient (25R9). Also, synonymous base changes were identified in PIK3CD and ERRFI1, see Table 3. None of the 
Table 3 DNA variations detected in the study

\begin{tabular}{|c|c|c|c|c|c|c|c|c|c|c|}
\hline Gene & $\begin{array}{l}\text { Gene } \\
\text { position }\end{array}$ & Patient & $\begin{array}{c}\text { NB } \\
\text { Stage }\end{array}$ & Ip-del & Outcome & Base change & Affected cases & Protein & $\begin{array}{l}\text { Normal } \\
\text { tissue from } \\
\text { the patient }\end{array}$ & $\begin{array}{l}\text { Healthy } \\
\text { controls }\end{array}$ \\
\hline \multicolumn{11}{|l|}{ Variations } \\
\hline \multirow{3}{*}{ PIK3CD } & & $24 R 3$ & 4 & Pos & NED & $469 C>A$ & Heterozygous C/A & LI57M & $\mathrm{C} / \mathrm{C}$ & $0 / 119$ \\
\hline & & $24 R 3$ & 4 & Pos & NED & $562 C>T$ & Heterozygous C/T & RI88W & $\mathrm{C} / \mathrm{C}$ & $0 / 119$ \\
\hline & Exon 16 & $19 R 6$ & 1 & Pos & DOD & $1965 G>A$ & Hemizygous $\mathrm{A} /-$ & M655I & $\mathrm{G} / \mathrm{A}$ & $0 / 113$ \\
\hline \multirow[t]{2}{*}{ ERRFII } & Exon 4 & $25 R 9$ & 2 & Neg & NED & $1028 \mathrm{~A}>\mathrm{G}$ & Heterozygous A/G & N343S & A/G & $0 / 111$ \\
\hline & Exon 4 & $24 \mathrm{R} 3$ & 4 & Pos & NED & $1186 C>A$ & Heterozygous C/A & L396L & $\mathrm{C} / \mathrm{C}$ & $0 / 111$ \\
\hline \multirow[t]{4}{*}{ PIK3CD } & Exon 8 & 18E4 & 4 & Pos & DOD & $935 C>G$ & Homozygous G/G & $\mathrm{S} 312 \mathrm{~S}$ & & $6 / 112$ \\
\hline & & 18E9 & 4 & Pos & DOD & $935 C>G$ & Heterozygous C/G & & & \\
\hline & Intron 7 & $23 R 7$ & 4 & Pos & DOD & IVS7-9G >C & Heterozygous G/C & & & $2 / 112$ \\
\hline & & $13 \mathrm{E} 6$ & 3 & Pos & DOD & IVS7-9G $>C$ & Homozygous C/C & & & \\
\hline \multirow[t]{2}{*}{ CASZI } & Exon 2 & I4R9 & $2 \mathrm{~B}$ & Pos & NED & $1-309 G>A$ & Heterozygous G/A & & & $1 / 89$ \\
\hline & Exon 8 & I7R4 & 4 & Pos & DOD & $1527 G>A$ & Heterozygous G/A & K509K & & $2 / 112$ \\
\hline
\end{tabular}

|p-del = I p-deletion; Pos = positive; Neg = negative; NED = no evidence of disease; $D O D=$ dead of disease.

A

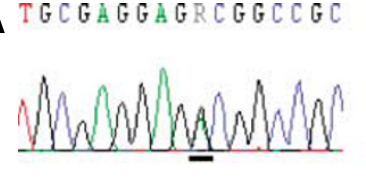

$T G C G A G G A G G C G G C C G C$

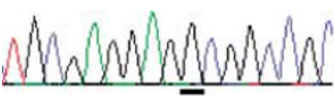

TGCGAGGAGGCGGCCGC

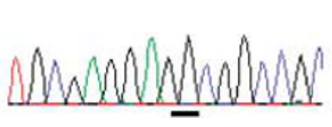

c

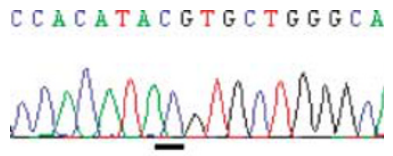

C CACATAYGTGCTGGGCA

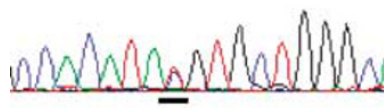

C C A C A T A T G T G C T G G G C A

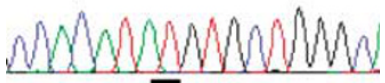

:TCCCGAACYGGGCCCTT

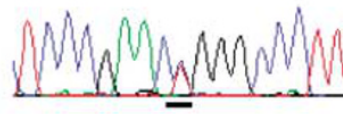

: TCCCGAACCGGGCCCTT

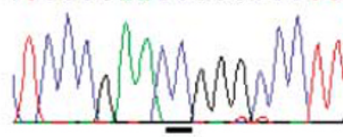

TCCCGAACCGGGCCCTTC

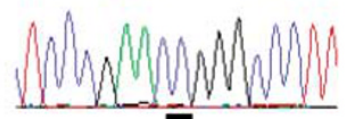

D

NB patient

Human

Mouse

Rat

Rabbit

Dog

Armadillo

Elephant

Opossum

Chicken

\section{A150T \\ L157M}

E E T A A

E E A A A

E E A A A

E E A A A

E E A A V

E E A A A

E E A A A

E E A A A

E E A A A

E E R A A
Q Q M G W

$Q Q L G W$

Q Q L GW

$Q Q L G W$

$Q Q L G W$

$Q Q L G W$

$Q Q L G W$

$Q Q L G W$

$Q Q L G W$

Q Q L S W
B ICCGAGATACACGTGCl

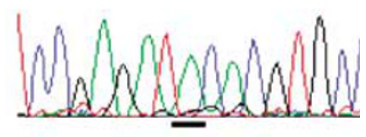

T C C G A G A T R C A C G T G C

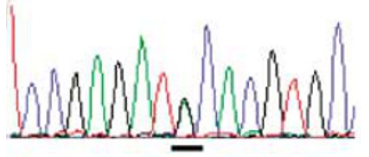

I C C GA GA T G C A C G T G C ।

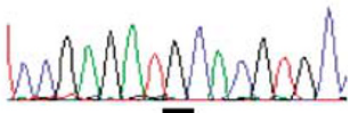

R188W

M655I

P NWA L SE I H V

PNRA L SEMH V

$S N R A L \quad S E M H V$

SNRPL SEM H V

P N R A L S E M H V

PSR A L S E M H V

PSRAL SEMHV

P N R V L S E M H V

PNRNL SEMHV

$P$ I K N I S E M H V

Figure 4 PIK3CD mutations in NB primary tumours. Bars under each chromatogram indicate the mutation position. (A) Variations in exon 5. Upper panel: Mutations 448G >A, 469C>A and 562C>T in patient 24R3 gave rise to amino-acid changes from Ala to Thr, Leu to Met and Arg to Trp, respectively. Middle panel: Normal tissue from patient 24R3. Lower panel: Healthy control individuals. (B) Variation in exon 16. Upper panel: 1965G > A mutation results in amino-acid change from Met to lle in patient I9R6. Middle panel: Normal tissue from patient I9R6, heterozygous for G/A. Lower panel: Healthy control individual. (C) Variation in exon 21. Upper panel: 266IT>C mutation in patient 19R6. Middle panel: Normal tissue from patient 19R6, heterozygous for T/C. Lower panel: Healthy control individual. (D) Alignment of amino-acid sequences. The putative mutations, marked with red, are located in conserved regions. 

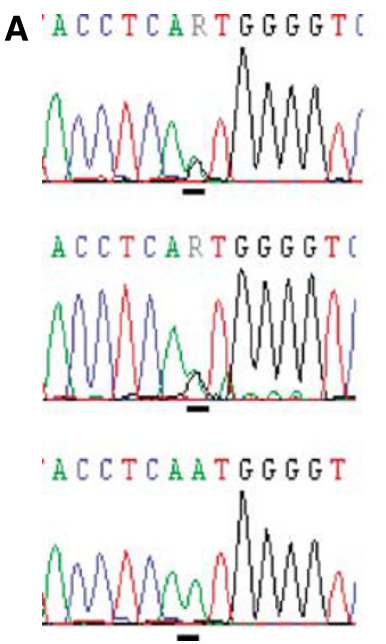

B attattacytactac

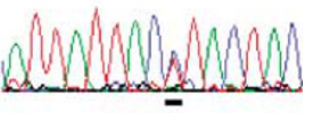

ATTATTACCTACTAC

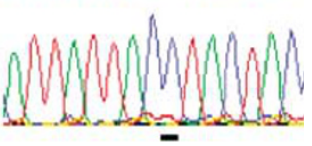

ATTATTACCTACTAC
C

NB patient $Y$ L S G V

Human $Y$ L N G V

Mouse $\quad Y L N G$ V

Rat $\quad Y L N G$ V

Rabbit $\quad Y$ L N G V

Dog $\quad Y L N G$ V

Armadillo $Y L N G$ V

Opossum $Y$ L N G V

Chicken $Y L N G$ V

Figure 5 ERRFII in exon 4 in NB tumours. Bars under each chromatogram indicate the mutation position. (A) Upper panel: The I028A > G mutation in patient 25R9 leads to an amino-acid substitution from Asn to Ser. Middle panel: Normal tissue from patient 25R9, heterozygous for A/G. Lower panel: Healthy control individual. (B) Upper panel: I I86C > A variation in patient 24R3. Middle panel: Normal tissue from patient 24R3, homozygous for the C allele. Lower panel: Healthy control individual. (C) Alignment of amino-acid sequences. The putative mutation, marked with red, is located in a highly conserved region.

alterations described above could be detected in any of 100 healthy control individuals ( $>200$ alleles). In addition to these tumourspecific variations, some novel polymorphisms were identified (Table 3).

\section{DISCUSSION}

1p-deletion is common both in NB and in other tumour types. Since methylation and other epigenetic features have been shown to be important mechanisms in the downregulation and repression of genes, we decided to study DNA methylation and histone deacetylation of genes in the NB/germ cell SRO we had previously defined in order to pinpoint specific genes with a possible involvement in NB. A number of NB cell lines were thus treated with the demethylating agent 5-Aza-dC or the deacetylase inhibitor TSA and the expression of a number of chromosome 1p36.1-2 genes were studied with and without treatment. The genes found to be upregulated after treatment of the NB cell lines were consequently considered to be tentative targets of epigenetic events in NB tumour initiation/progression. The genes thus identified were subjected to (i) bisulphite sequencing of the CpG islands, (ii) analysis of expression in a large number of primary tumours and (iii) mutation screening in the coding regions.

Expression of the ERRFI1, PIK3CD, RBP7 and CASZ1 genes increased after treatment with the deacetylase inhibitor TSA, suggesting that these genes are regulated by histone modifications in NB. PIK3CD, RBP7 and CASZ1 also exhibited changes in expression in some of the cell lines tested after treatment with the demethylating agent $5-\mathrm{Aza}-\mathrm{dC}$, indicating that these genes could also be silenced by DNA methylation.

The genes we identified as potential targets of epigenetic modification were sequenced using tumour DNA modified with the bisulphite method in order to explore methylation status. The gene sequences were studied with the $\mathrm{CpG}$ island searcher and CpGProD (Figure 1). ERRFI1 (MIG-6) was not subject to this analysis since its expression was not upregulated after treatment with 5-Aza-dC; furthermore, it displayed a higher level of expression in patients with unfavourable outcome than in patients with favourable outcome.

In our data, there were generally more methylated $\mathrm{CpG}$ sites in NB cell lines than in primary NB tumours. This pattern has also been seen in other studies, for example of CASP8 and RASSF1A (Lazcoz et al, 2006). No consistent CpG methylation sites in both NB cell lines and primary tumours differing from those of control blood DNA could be identified. Since NB is derived from neural crest progenitor cells, blood DNA might not be a good control. One could speculate that the normal progenitor cells should be completely unmethylated while the cells that develop into NB are methylated, but this is only a speculation. However, since only portions of one of the $\mathrm{CpG}$ islands in CASZ1 and PIK3CD (Figure 1) were methylated, it is not likely that this account for the low expression of the genes in unfavourable tumours. The increase in expression after treatment with 5 -Aza-dC could be due to the methylation seen in these fragments in the cell lines or alternatively be explained by other normally methylated genes being activated as a result of the treatment which could have an enhancing effect on the transcription of PIK3CD and CASZ1. Enhancers or other regulatory sequences located outside the analysed region could also be affected by methylation. Other means of silencing could also be involved, as histone modifications, since treatment with TSA increases expression in the NB cell lines. The fragment analysed in the $\mathrm{CpG}$ island of $R B P 7$ was unmethylated in the cell lines used (data not shown, available on request).

The RNA expression analysis showed a decrease in PIK3CD and CASZ1 in aggressive $\mathrm{NB}$, compared to more favourable $\mathrm{NB}$ tumours, for PIK3CD this decrease was significant also after Bonferroni correction $(P=0.001)$. These data are concordant with a previous study of expression in NB of 30 genes in the $1 \mathrm{p} 36.2$ region from our group (Fransson et al, 2007). The NB tumour material used in that study is overlapping with this previous study; however in this study, we have used clinical outcome criteria for grouping the tumours. One could speculate that the difference in expression could be due to a dosage effect since a major proportion of the unfavourable NB tumours harbours a deletion of $1 \mathrm{p}$.

The RNA expression analysis of ERRFI1 showed a two-fold increase in unfavourable tumour compared to favourable, seemingly contradicting the results of another study that found ERRFI1 downregulation in breast tumours in patients with poor prognosis (Amatschek et al, 2004). This may reflect different functions, depending on tumour type, but it could also indicate that more advanced stage tumours grow more rapidly since ERRFI1 expression can be induced by a variety of stimuli such as 
growth factors, hypoxia and stress factors (Saarikoski et al, 2002; Pante et al, 2005).

We also performed mutation screening of all coding regions of the four genes, ERRFI1, PIK3CD, RBP7 and CASZ1, by DNA sequencing. Three tumours with amino-acid changes were identified. Tumour 24R3 has three nonsynonymous mutations in the gene PIK3CD. The tumour harbours 1 -deletion, but has two alleles at the site of the mutations according to DNA sequencing (see Figure 4), hence the deletion does not cover this region or more probably, the wild-type allele comes from contaminating normal cells in the DNA sample, indicated by single-nucleotide polymorphisms (SNP) array analysis carried out on the tumour (data not shown). The mutations are de novo mutations since they are not found in the constitutional DNA. Tumour 19R6 also harbours a nonsynonymous DNA mutation, M655I. The tumour is $1 \mathrm{p}$-deleted and the normal tissue from the patient is heterozygous for the base variation. A nonsynonymous DNA mutation was also identified in tumour 25R9 (intact 1p) in the ERRFI1 gene. The variation is also found in constitutional DNA from the patient. Also, one synonymous base change was found in ERRFI1 and two in PIK3CD (one located in intronic sequence). None of the variations mentioned above were detected in any of more than 100 healthy control individuals (more than 200 alleles), indicating that these changes are indeed mutations. Although, it should be noted that samples with mutations are limited. The tumour from patient $25 \mathrm{R} 9$ have intact chromosome $1 \mathrm{p}$, so the mutation only constitute one 'hit'. The mutation in tumour 19R6 in the PIK3CD fits the two-hit hypothesis of tumour suppressor inactivation (Knudson, 1971) since it is also 1p deleted. This is probably also true for $24 \mathrm{R} 3$ if assuming that the wild-type allele comes from contaminating normal material as indicated by the SNP array analysis of this tumour. Some alterations not annotated as single-nucleotide polymorphisms (SNP) in the UCSC genome browser were also found in the study, indicating that rare polymorphisms have been detected.

The known functions of the four genes are interesting in relation to NB. ERRFI1, also known as MIG-6 or RALT, can be induced by stress, growth factors and the protein Ras. ERRFI1 has recently been reported by Zhang et al (2007) to be mutated in human nonsmall-cell lung cancer cell lines and in one primary tumour. Loss of activity contributes to the initiation of lung carcinogenesis and also other tumour types. RBP7 is a cellular retinoid-binding protein. Retinol is important in embryonic development. $R B P 7$ is epigenetically silenced by DNA methylation in the promoter region in a high frequency of nasopharyngeal carcinomas as well as in some cancer cell lines (colon, prostatic and ovarian cancer) (Kwong et al, 2005). CASZ1 is a putative homologue to the zincfinger transcription factor Castor, required for CNS neuronal development in Drosophila melanogaster, where it is involved in neuronal cell lineage specification (Mellerick et al, 1992; Edenfeld et al, 2002). Liu et al (2006) has recently presented cloning and characterisation of the human homologue. They reported that the expression of CASZ1 is increased when cells of neural origin are induced to differentiation. PIK $3 C D$, encoding the protein $\mathrm{p} 110 \delta$, is a catalytic subunit in class IA phosphoinositide 3-kinase (PI3K). Phosphoinositide 3-kinase are important in regulating signalling involved in cell cycle progression, cell growth, survival and migration. Class 1 PI3K encompasses four isoforms, besides $\mathrm{p} 110 \delta$, also p110 $\alpha$ (PIK3CA), p110 $\beta$ (PIK3CB) and p110 $\gamma$ (PIK3CG). The four isoforms are believed to have distinct functions and are also regulated differently (Chang et al, 1997). Gain of function of the $\alpha$ subunit is common in human cancers by overexpression or mutations (Samuels and Velculescu, 2004; Samuels et al, 2004). In our NB tumour material, we could not identify any mutations in the PIK3CA gene (data not shown) and Dam et al (2006) have reported only infrequent mutations in their NB material. The PI3 kinases are generally considered to function as oncogenes. Although, our data could not find any indications of PIK $3 C D$ acting as an oncogene in NB based on the following aspects: (a) PIK3CD is located in a chromosomal region where LOH is common in NB as well as in other paediatric tumours (Grundy et al, 1994; Benn et al, 2000; Bridge et al, 2000), (b) gene expression studies show a downregulation of transcripts in high-stage NB compared to low-stage (consistent with findings of an expression profiling of selected genes of chromosome region 1p35-36 reported by Janoueix-Lerosey et al, 2004), (c) 5-Aza-dC and TSA studies indicate that PIK3CD could be influenced by epigenetic regulation in NB, (d) putative mutations have been identified. One could speculate that the mutations identified are gain-of-function mutations that would support the concept that the PIK3CD gene could act as an oncogene in NB. The downregulation in gene transcripts seen in high-stage compared to low-stage tumours could be an upregulation in both high- and low-stage NB compared to the transcription in the cells from which the NB tumour cells arise. Although, expression analysis of the tumours that harbour the mutations show that the gene is low expressed (data not shown). This contradicts the concept of the mutations being gain-of-function mutations. Further studies to evaluate the function of the PIK3CD gene in NB are ongoing.

In summary, we have undertaken a broad analysis of the region located in our NB/germ cell SRO of deletions. Epigenetic regulation, mRNA expression and mutation screening at the DNA level were explored. A group of genes have been identified as epigenetically affected in NB cell lines; the PIK3CD gene stands out as the most intriguing, since it also carries mutations in primary tumours, two patients with nonsynonymous mutations were identified. The mRNA expression of this gene is downregulated in unfavourable, compared to favourable, NB tumours. Treatment of NB cell lines with the histone deacetylase inhibitor TSA led to increased gene transcription, indicating that the gene could be epigenetically regulated. DNA mutations were also identified in the ERRFI1 gene. The current study further strengthens the concept of chromosome region $1 \mathrm{p} 36$ being important in the development of NB tumours and supports the hypothesis that there could be several genes in the region required for the initiation and/or progression of this tumour.

\section{ACKNOWLEDGEMENTS}

This work was supported by the Swedish Knowledge Foundation through the Industrial $\mathrm{PhD}$ programme in Medical Bioinformatics at the Strategy and Development Office (SDO) at Karolinska Institutet and with grants from the Swedish Cancer Society, the Children's Cancer Foundation, the King Gustav V Jubilee Clinic Cancer Research Foundation, the Assar Gabrielsson Foundation, the Wilhelm and Martina Lundgren Research Foundation and the Sahlgrenska University Hospital Foundation. We thank the Swegene Gothenburg Genomics resource unit for access to the ABI 7900HT Sequence Detection System and the ABI 3730 Sequencer.

\section{REFERENCES}

Abel F, Sjöberg R-M, Ejeskär K, Krona C, Martinsson T (2002) Analyses of apoptotic regulators CASP9 and DFFA at 1P36.2, reveal rare allele variants in human neuroblastoma tumours. Br J Cancer 86: 596-604
Abel F, Sjöberg R-M, Krona C, Nilsson S, Martinsson T (2004) Mutations in the N-terminal domain of DFF45 in a primary germ cell tumor and in neuroblastoma tumors. Int J Oncol 25: 1297-1302 
Abel F, Sjöberg RM, Nilsson S, Kogner P, Martinsson T (2005) Imbalance of the mitochondrial pro- and anti-apoptotic mediators in neuroblastoma tumours with unfavourable biology. Eur J Cancer 41: 635-646

Amatschek S, Koenig U, Auer H, Steinlein P, Pacher M, Gruenfelder A, Dekan G, Vogl S, Kubista E, Heider KH, Stratowa C, Schreiber M, Sommergruber W (2004) Tissue-wide expression profiling using cDNA subtraction and microarrays to identify tumor-specific genes. Cancer Res 64: $844-856$

Bauer A, Savelyeva L, Claas A, Praml C, Berthold F, Schwab M (2001) Smallest region of overlapping deletion in 1p36 in human neuroblastoma: a $1 \mathrm{Mbp}$ cosmid and PAC contig. Genes Chromosomes Cancer 31: $228-239$

Benn DE, Dwight T, Richardson AL, Delbridge L, Bambach CP, Stowasser M, Gordon RD, Marsh DJ, Robinson BG (2000) Sporadic and familial pheochromocytomas are associated with loss of at least two discrete intervals on chromosome 1p. Cancer Res 60: 7048-7051

Bridge JA, Liu J, Weibolt V, Baker KS, Perry D, Kruger R, Qualman S, Barr F, Sorensen P, Triche T, Suijkerbuijk R (2000) Novel genomic imbalances in embryonal rhabdomyosarcoma revealed by comparative genomic hybridization and fluorescence in situ hybridization: an intergroup rhabdomyosarcoma study. Genes Chromosomes Cancer 27: $337-344$

Carén H, Ejeskär K, Fransson S, Hesson L, Latif F, Sjöberg RM, Krona C, Martinsson T (2005) A cluster of genes located in 1 p36 are downregulated in neuroblastomas with poor prognosis, but not due to $\mathrm{CpG}$ island methylation. Mol Cancer 4: 10

Caron H, Spieker N, Godfried M, Veenstra M, van Sluis P, de Kraker J, Voute P, Versteeg R (2001) Chromosome bands 1p35-36 contain two distinct neuroblastoma tumor suppressor loci, one of which is imprinted. Genes Chromosomes Cancer 30: $168-174$

Caron H, van Sluis P, de Kraker J, Bokkerink J, Egeler M, Laureys G, Slater R, Westerveld A, Voute PA, Versteeg R (1996) Allelic loss of chromosome $1 \mathrm{p}$ as a predictor of unfavorable outcome in patients with neuroblastoma. $N$ Engl J Med 334: 225-230

Chang HW, Aoki M, Fruman D, Auger KR, Bellacosa A, Tsichlis PN, Cantley LC, Roberts TM, Vogt PK (1997) Transformation of chicken cells by the gene encoding the catalytic subunit of PI 3-kinase. Science 276: $1848-1850$

Chen YZ, Soeda E, Yang HW, Takita J, Chai L, Horii A, Inazawa J, Ohki M, Hayashi Y (2001) Homozygous deletion in a neuroblastoma cell line defined by a high-density STS map spanning human chromosome band 1p36. Genes Chromosomes Cancer 31: 326-332

Clark SJ, Harrison J, Paul CL, Frommer M (1994) High sensitivity mapping of methylated cytosines. Nucleic Acids Res 22: 2990-2997

Dam V, Morgan BT, Mazanek P, Hogarty MD (2006) Mutations in PIK3CA are infrequent in neuroblastoma. BMC Cancer 6: 177

Edenfeld G, Pielage J, Klambt C (2002) Cell lineage specification in the nervous system. Curr Opin Genet Dev 12: $473-477$

Ejeskär K, Abel F, Sjöberg R, Bäckström J, Kogner P, Martinsson T (2000) Fine mapping of the human preprocortistatin gene (CORT) to neuroblastoma consensus deletion region $1 \mathrm{p} 36.3 \rightarrow \mathrm{p} 36.2$, but absence of mutations in primary tumors. Cytogenet Cell Genet 89: 62-66

Ejeskär K, Sjöberg R-M, Abel F, Kogner P, Ambros PF, Martinsson T (2001) Fine mapping of a tumour suppressor candidate gene region in $1 \mathrm{p} 36.2-$ 3 , commonly deleted in neuroblastomas and germ cell tumours. Med Pediatr Oncol 36: 61-66

Fransson S, Martinsson T, Ejeskär K (2007) Neuroblastoma tumors with favorable and unfavorable outcomes: significant differences in mRNA expression of genes mapped at 1p36.2. Genes Chromosomes Cancer 46: $45-52$

Gale GB, D'Angio GJ, Uri A, Chatten J, Koop CE (1982) Cancer in neonates: the experience at the Children's Hospital of Philadelphia. Pediatrics 70: 409-413

Grundy PE, Telzerow PE, Breslow N, Moksness J, Huff V, Paterson MC (1994) Loss of heterozygosity for chromosomes $16 \mathrm{q}$ and $1 \mathrm{p}$ in Wilms tumors predicts an adverse outcome. Cancer Res 54: 2331-2333

Janoueix-Lerosey I, Novikov E, Monteiro M, Gruel N, Schleiermacher G, Loriod B, Nguyen C, Delattre O (2004) Gene expression profiling of 1p35-36 genes in neuroblastoma. Oncogene 23: 5912-5922
Knudson Jr AG (1971) Mutation and cancer: statistical study of retinoblastoma. Proc Natl Acad Sci USA 68: 820-823

Krona C, Ejeskär K, Abel F, Kogner P, Bjelke J, Björk E, Sjöberg R-M, Martinsson T (2003) Screening for gene mutations in a $500 \mathrm{~kb}$ neuroblastoma tumor suppressor candidate region in chromosome 1p; mutation and stage-specific expression in UBE4B/UFD2. Oncogene 22: $2343-2351$

Krona C, Ejeskär K, Carén H, Abel F, Sjöberg R-M, Martinsson T (2004) A novel 1p36.2 located gene, APITD1, with tumour-suppressive properties and a putative p53-binding domain, shows low expression in neuroblastoma tumours. Br J Cancer 91: 1119-1130

Kwong J, Lo KW, Chow LS, To KF, Choy KW, Chan FL, Mok SC, Huang DP (2005) Epigenetic silencing of cellular retinol-binding proteins in nasopharyngeal carcinoma. Neoplasia 7: 67-74

Lazcoz P, Munoz J, Nistal M, Pestana A, Encio I, Castresana JS (2006) Frequent promoter hypermethylation of RASSF1A and CASP8 in neuroblastoma. BMC Cancer 6: 254

Liu Z, Yang X, Tan F, Cullion K, Thiele CJ (2006) Molecular cloning and characterization of human Castor, a novel human gene upregulated during cell differentiation. Biochem Biophys Res Commun 344: 834-844

Martinsson T, Sjöberg R-M, Hallstensson K, Nordling M, Hedborg F, Kogner P (1997) Delimitation of a critical tumour suppressor region at distal 1p in neuroblastoma tumours. Eur J Cancer 33: 1997-2001

Martinsson T, Sjöberg R-M, Hedborg F, Kogner P (1995) Deletion of chromosome $1 \mathrm{p}$ loci and microsatellite instability in neuroblastomas analyzed with short-tandem repeat polymorphisms. Cancer Res 55: $5681-5686$

Mellerick DM, Kassis JA, Zhang SD, Odenwald WF (1992) Castor encodes a novel zinc finger protein required for the development of a subset of CNS neurons in drosophila. Neuron 9: 789-803

Ohira M, Kageyama H, Mihara M, Furuta S, Machida T, Shishikura T, Takayasu H, Islam A, Nakamura Y, Takahashi M, Tomioka N, Sakiyama S, Kaneko Y, Toyoda A, Hattori M, Sakaki Y, Ohki M, Horii A, Soeda E, Inazawa J, Seki N, Kuma H, Nozawa I, Nakagawara A (2000) Identification and characterization of a $500-\mathrm{kb}$ homozygously deleted region at $1 \mathrm{p} 36.2-\mathrm{p} 36.3$ in a neuroblastoma cell line. Oncogene 19: $4302-4307$

Pante G, Thompson J, Lamballe F, Iwata T, Ferby I, Barr FA, Davies AM, Maina F, Klein R (2005) Mitogen-inducible gene 6 is an endogenous inhibitor of HGF/Met-induced cell migration and neurite growth. J Cell Biol 171: $337-348$

Paulin R, Grigg GW, Davey MW, Piper AA (1998) Urea improves efficiency of bisulphite-mediated sequencing of 5'-methylcytosine in genomic DNA. Nucleic Acids Res 26: 5009-5010

Ponger L, Mouchiroud D (2002) CpGProD: identifying CpG islands associated with transcription start sites in large genomic mammalian sequences. Bioinformatics 18: 631-633

Saarikoski ST, Rivera SP, Hankinson O (2002) Mitogen-inducible gene 6 (MIG-6), adipophilin and tuftelin are inducible by hypoxia. FEBS Lett 530: $186-190$

Samuels Y, Velculescu VE (2004) Oncogenic mutations of PIK3CA in human cancers. Cell Cycle 3: 1221-1224

Samuels Y, Wang Z, Bardelli A, Silliman N, Ptak J, Szabo S, Yan H, Gazdar A, Powell SM, Riggins GJ, Willson JK, Markowitz S, Kinzler KW, Vogelstein B, Velculescu VE (2004) High frequency of mutations of the PIK3CA gene in human cancers. Science 304: 554

Takai D, Jones PA (2002) Comprehensive analysis of CpG islands in human chromosomes 21 and 22. Proc Natl Acad Sci USA 99: 3740-3745

Vandesompele J, De Preter K, Pattyn F, Poppe B, Van Roy N, De Paepe A, Speleman F (2002) Accurate normalization of real-time quantitative RT PCR data by geometric averaging of multiple internal control genes. Genome Biol 3, RESEARCH0034.1-0034.11

White PS, Thompson PM, Gotoh T, Okawa ER, Igarashi J, Kok M, Winter C, Gregory SG, Hogarty MD, Maris JM, Brodeur GM (2005) Definition and characterization of a region of $1 \mathrm{p} 36.3$ consistently deleted in neuroblastoma. Oncogene 24: 2684-2694

Zhang YW, Staal B, Su Y, Swiatek P, Zhao P, Cao B, Resau J, Sigler R, Bronson R, Vande Woude GF (2007) Evidence that MIG-6 is a tumorsuppressor gene. Oncogene 26: 269-276 